\section{$\underset{\substack{\text { hommes } \\ \text { \& migrations }}}{ }$}

\section{Hommes \& migrations}

Revue française de référence sur les dynamiques

migratoires

\section{$1299 \mid 2012$}

Musulmanes et féministes en Grande-Bretagne

\title{
Linda Lê, Lame de fond
}

Paris, Christian Bourgois, 2012, 277 pages, 17 euros

\section{Mustapha Harzoune}

\section{(2) OpenEdition \\ 1 Journals}

Édition électronique

URL : http://journals.openedition.org/hommesmigrations/1440

DOI : 10.4000/hommesmigrations. 1440

ISSN : 2262-3353

Éditeur

Musée national de l'histoire de l'immigration

\section{Édition imprimée}

Date de publication : 1 septembre 2012

Pagination : 151-152

ISSN : 1142-852X

\section{Référence électronique}

Mustapha Harzoune, «Linda Lê, Lame de fond », Hommes \& migrations [En ligne], 1299 | 2012, mis en ligne le 29 mai 2013, consulté le 22 septembre 2020. URL : http://journals.openedition.org/

hommesmigrations/1440 ; DOI : https://doi.org/10.4000/hommesmigrations.1440

Ce document a été généré automatiquement le 22 septembre 2020.

Tous droits réservés 


\title{
Linda Lê, Lame de fond
}

Paris, Christian Bourgois, 2012, 277 pages, 17 euros

\author{
Mustapha Harzoune
}

\section{RÉFÉRENCE}

Linda Lê, Lame de fond, Paris, Christian Bourgois, 2012, 277 pages, 17 euros.

1 La lame de fond, c'est ce que doit l'apparent ordonnancement des vies aux profondeurs des histoires personnelles, c'est ce qui, brutalement, remonte à la surface des êtres et des existences pour chambouler ces ordonnancements plus ou moins lisses et stables, les arrangements avec le réel, avec les siens, les vivants comme les fantômes. Une lame de fond va emporter le monde de trois femmes et la vie d'un homme. Le livre est écrit à quatre voix, celle de Van et de Lou, son épouse, celle de Laure, leur adolescente de fille, et la voix d'Ulma, la sœur de Van. Ulma déboule dans la vie de Van, elle surgit d'un passé lointain, repoussé, oublié, inconnu même, elle rouvre chez lui un continent d'émotions et d'interrogations. "Je ne m'appesantissais pas sur mon état d'émigré, dit Van, j'avais barré d'un trait des pages de ma biographie. (...) Ne pas avoir ma patrie collée à mes souliers, délier toutes les amarres sans sombrer corps et biens, remettre le compteur à zéro à partir du moment où j'avais secoué de mes épaules la poussière du passé, ne rien oublier, ne rien renier, mais me distancier des chiens qui retournent à leur vomi, tempérer mon hyperesthésie affective en me faisant violence." Cette posture sera bousculée par une lettre qu'Ulma se décide, après des années d'hésitations, à adresser à son frère dont elle a découvert l'existence au cours de sa quête vietnamienne des origines. Van, lui, avait comme tiré un trait sur ce passé, il habitait un autre lieu : “Les dernières années, je n'avais plus pensé à mon père ni à ma ville natale, j'étais si bien intégré que je n'avais de l'Asiatique que l'apparence et de vietnamien que mon nom. Je n'étais pas un de ces exilés qui languissaient loin de leur patrie. Ma demeure est hors du camp, disait Benjamin Fondane (...). Moi non plus je ne savais où était ma demeure. (...) Je ne nouais pas de liens avec ceux qui venaient du même pays que moi. Ulma était pareillement dans un entre-deux qui rendait problématique tout acclimatement. Eurasienne descendant d'un immigré turc, elle était l'incarnation du 
métissage qui donnait des enfants splendides, mais parfois inadaptés." Van vient de mourir. Ce ci-devant réfugié vietnamien, débarqué à l'adolescence, passionné de littérature, était un de ces métèques qui, comme hier un Jean El-Mouhouv Amrouche, en remontrent à plus d'un sur la littérature et la langue françaises. Il était d'ailleurs correcteur dans une maison d'édition... Son identité était une identité de langue et de mots : "Mes livres de chevet ne sentaient pas le terroir, ils étaient écrits par des génies qui ne se faisaient pas gloire d'appartenir à telle ou telle nation. Aucune frontière ne les arrêtait, même si, dans certains cas, ils n'avaient pas eu à sortir de leur jardin pour connaitre le monde." Et quand il lui arrivait de se poser des questions sur lui-même, c'est "en tant qu'individu désadapté, pas en tant qu'exilé qui soupirait après la joie de retrouver son paradis perdu, le Vietnam". Le récit s'ouvre sur l'accident dont Van vient d'être victime. C'est de sa tombe qu'il parle. Une Austin lui a foncé dessus du côté du boulevard Saint-Germain. Au volant, il a reconnu son épouse, Lou. À partir de ce drame, chacun remonte le fil de son histoire personnelle, livre sa part de vérité sur les événements qui allaient conduire à la mort de Van. Le récit polyphonique est scandé en quatre temps ("Au cœur de la nuit", "Aube", "Midi" et "Crépuscule"), parfaitement maîtrisés, souvent bouleversants. Linda Lê déploie un style rythmé, dynamique, enjoué par certains côtés pour relater ce qui, tout de même, relève du tragique. Elle joue avec la langue, multiplie les registres, mêle l'oralité baignée d'anglicismes d'une adolescente à l'épure stylistique et au souci du mot juste d'un immigré qui a fait du français sa nouvelle patrie. Tout cela est élégant et c'est avec aisance et efficacité que l'auteure portraiture ses contemporains à l'image de Van et Lou, ce couple des cosmopolites quartiers de Belleville et de Ménilmontant, lui qui biberonne à l'alcool, elle soucieuse de n'ingurgiter que du bio et du sain. C'est avec sensibilité qu'elle décrit les rapports entre père et fille (Van et Laure, mais aussi Lou et son propre père), ou la place d'une enfant au milieu d'un couple qui, après vingt ans de mariage, se délite, miné par la monotonie. Elle pointe la question de la responsabilité (plutôt de l'irresponsabilité) individuelle au regard de l'engagement pour des causes collectives, semble ici célébrer la dignité version féminine portée par la mère de Van, la grand-mère d'Ulma et même par le personnage de Lou. Cette Lame de fond est une plongée dans les entrailles des mémoires familiales, des origines incertaines et des identités mêlées. En toile de fond, résonnent, comme un écho lointain, les bruits de l'épisode colonial, ici vietnamien. De cet autre temps, quelques tubercules meurtriers restent accrochés à l'âme nationale des décennies après, comme ceux qui gangrènent la mère de Lou. Tandis que "le fleuve détourné" de l'indépendance apparait au détour de tel ou tel propos, en France, une autre lame de fond pourrait bien bousculer le roman national: "Non, moi j'exigeais plus: une vraie prise de pouvoir par les habitants des villesdortoirs, un déferlement de sang-mêlé en Gaule, de quoi troubler le sommeil des adversaires du métissage." 